DOI 10.37882/2500-3682.2021.09.06

\title{
К ВОПРОСУ ОБ ОСНОВНЫХ ПОДХОДАХ К тИПОЛОгИИ КУЛЬТУР'
}

\section{TO THE QUESTION ABOUT THE BASIC APPROACHES TO THE TYPOLOGY OF CULTURES}

\section{Z. Kalandarishvili \\ D. Gezenko}

Summary: In this research, the authors discuss the problem associated with the main approaches to the typology of cultures. Culture acts as a criterion in determining the quality side of the legal reality of people's lives. According to the authors of the article, the variety of different approaches to the typology of cultures testifies to the complexity and ambiguity of this problem. On this issue, researchers are looking for new directions and new approaches.

Keywords: law, society, culture, typology of cultures, civilizationa approach, formational approach, semiotic approach.
$\mathrm{P}$ ассмотрим наиболее распространенные в современной научной мысли подходы к типологии культур. Стоит отметить, что наиболее распространенными являются цивилизационный и формационный подходы, которые дополняют друг друга и помогают создавать многомерную, объемную картину действительности и, в том числе, картину развития, так как народы и культуры любой эпохи в прошлом, настоящем и будущем не могут существовать вне конкретных цивилизаций, возникая, развиваясь и иногда умирая в пределах того или иного автономного пространства, в пределах той или иной культурной общности людей, имеющих общую историю, религиозные, социально-психологические, иные духовные, поведенческие и прочие традиции и стереотипы, сходные экономические основания, политико-правовое устройство и т.д. В пределах любой формации существуют различные цивилизации, последние, развиваясь, переходят, как правило, из одной формации в другую, либо погибают, исчезают, либо, наконец, некоторые цивилизации застывают в своем развитии, оставаясь в пределах одной формации.

В свое время П.А. Сорокин построил типологию культур на основе ценностного критерия, примененного диахронно. Ученый выделил идеациональную, чувственную и идеалистическую культуры и соответствующие им
Каландаришвили Зураб Нодарович

К.ю.н., к.п.н., профеессор, Санкт-Петербургский Гуманитарный Университет Профсоюзов zurab.kalandarishvili@yandex.ru

Гезенко Дарья Павловна

Старший преподаватель, Санкт-Петербургский Гуманитарный Университет Профсоюзов billy_92@mail.ru

Аннотация: В своем исследовании авторы рассуждают о проблеме, связанной с основными подходами к типологии культур. Культура выступает критерием в определении качественной стороны правовой реальности жизни людей. По мнению авторов статьи, многообразие различных подходов к типологии культур свидетельствует о сложности и неоднозначности этой проблемы. По данному вопросу исследователями ставится поиск новых направлений и новых подходов.

Ключевые слова: право, общество, культура, типология культур, цивилизационный подход, формационный подход, семиотический подход.

правовые культуры. Предложенная ученым типология культур позволяет выявить влияние ценностей на специфику коммуникаций в рамках каждой из культур и соответственно уяснить существующие между ними различия.

Идеациональная культура характеризуется следующими основными чертами: 1) реальность понимается как нематериальное, непреходящее, вечное Бытие; 2) цели и потребности общества, в основном, духовные; 3) степень их удовлетворения - максимальная и на высочайшем уровне; 4) способом их удовлетворения является добровольная минимизация большинства физических потребностей [1, с.18].

Таким образом, идеациональная культура - это религиозная культура, в которой главной целью является Бог.

На основе вариаций четвертого пункта П.А. Сорокин выделяет два основных подвида идеациональной ментальности: аскетический идеационализм и активный идеационализм. Первый ищет удовлетворения потребностей и реализации целей путем чрезмерной минимизации плотских потребностей и даже отказа от них, что сопровождается полной отрешенностью от чувственного мира и собственного тела, рассматриваемых как не- 
что нереальное, как иллюзия.

Второй ищет «удовлетворения потребностей и реализации целей не только путем минимизации телесных потребностей индивидов, но также путем преобразования чувственно воспринимаемого социокультурного мира в направлении духовной реальности и целей, избранных в качестве основных ценностей». Носители активного идеационализма не бегут от мира, как иллюзии, но стремятся приблизить его к Богу, спасти не только свои души, но и души других людей [5, с.496].

В чувственной культуре реально считается только то, что воспринимается органами чувств. В такой культуре отсутствует вера в сверхчувственную реальность, находящуюся за пределами чувственных ощущений. Потребности и стремления носителя чувственной ментальности - в основном физические, и все делается для того, чтобы эти потребности были максимально удовлетворены. При этом способ их реализации заключается не в преобразовании духовного мира человека, а в преобразовании и эксплуатации внешнего мира. Таким образом, чувственная культура - это светская культура, главная ценность которой - человек с набором нуждающихся в удовлетворении разнообразных, прежде всего, чувственных потребностей. Примером чувственной культуры является для П.А. Сорокина современная западная культура, главный принцип которой состоит в обслуживании физических потребностей индивидуума.

В системе социального регулирования при чувственной культуре отсутствует апелляция к сверхчувственным ценностям. Личные и имущественные отношения людей управляются с точки зрения их целесообразности, полезности либо для общества в целом, либо для правящей элиты. Идеациональные ценности не играют никакой роли в ограничении или контроле этих утилитарных побуждений. Система регулирования определяется исключительно чувственными побуждениями. Соответственно все отношения - либо договорные (на основе совместного соглашения сторон), либо общеобязательные (навязываемые сильными слабым) и санкционированы законом.

Идеалистическая культура, согласно П.А. Сорокину, представляет собой смешанный, «логически интегрированный» вид культуры. В количественном отношении идеалистическая культура есть более или менее сбалансированное соединение идеациональных и чувственных элементов с преобладанием, однако, элементов идеациональных. В качественном отношении она синтезирует посылки обоих типов в одно внутренне согласованное и гармоничное единство. Реальность для нее многогранна, имеет аспекты и непреходящего Бытия, и вечно изменяющегося Становления - духовного и материального. Его потребности и цели - духовные и материальные, однако материальные не подчинены духовным. Способы их реализации заключается и в самосовершенствовании, и в преобразовании внешнего чувственно воспринимаемого мира: другими словами, эта ментальность и идеациональному, и чувственному воздает suum cuique (каждому свое). Соответственно, такой гармоничный характер имеет и идеалистическая правовая культура. Историческим примером такой культуры является для П.А. Сорокина европейская культура XIII-XIV вв., когда произошло органическое слияние двух культурных принципов - приходящего в упадок принципа идеациональной культуры и нового принципа зарождающейся чувственной культуры. Таким образом, западная культура, полагает П.А. Сорокин, прошла в своем развитии три стадии - идеациональную (V-XII вв.), идеалистическую (XIII-XIV вв.) и чувственную (с XVI в. и по настоящее время). Такие стадии можно выделить в рамках любой культуры.

Сторонник семиотического подхода Ю.М. Лотман выделяет зависимость типа культуры от типа (средств) коммуникации. Ученый понимает коммуникацию как передачу информации при помощи определенных средств. Смена типа коммуникации влечет за собой изменение глобальных культурных типов в истории. Так, первая смена происходит в связи с переходом от бесписьменных культур к письменным, вторая - в связи с появлением печатного станка и возникновением «книжной» культуры, третья - основана на распространении новых средств массовой информации. Четвертый тип - это тот тип культуры, к которому относят современные общества: тип новейших информационных технологий. Информационным обществам соответствует сетевой тип культуры, теория которого активно разрабатывается в западной социологической и политико-правовой мысли. В данном типе культуры оказываются максимально востребованными коммуникативные способности человека, создающего вокруг себя «сеть» коммуникаций, что позволяет сделать более эффективным процесс обмена идеями, информацией и ресурсами [2, с.104].

Из интересных научных работ последних лет, где объектом изучения являлась бы проблема типологии культуры, следует учесть исследования А.П. Семитко. Типология культур по концепции ученого должна базироваться на учете особенностей и черт всех основных сфер человеческой жизнедеятельности и культуры. Однако этот учет не должен подменять собой анализ собственно духовной сферы жизни общества [3, с.24].

Центральным положением в работе А.П. Семитко является предположение и обоснование новой «двучленной» типологии культуры. В развитии последней выделяются два исторических типа: социоцентрический и персоноцентрический типы культуры. Основанием выделения названных типов является положение личности 
в социуме и уровень обеспечиваемой правом свободы человека. Как полагает А.П. Семитко, в настоящее время развитие личности в целом идет от социоцентристского к персоноцентристскому типу культуры.

В социоцентристском типе культуры приоритетными и основополагающими являются идея и интересы общего целого, общины, государства и общества, отдельных их представителей (правители, правящая элита, немногочисленный господствующий класс и т.д.). Не персона, не личность, а социальность, социум находятся здесь в центре социальной защиты, в центре культуры, отсюда - социоцентризм. Этот тип культуры характеризуется не только указанными фундаментальными, базовыми ценностями, но и своими особыми, специфическими правовыми средствами: запретами, императивами, разветвленными и многочисленными санкциями, подчеркнутым публично-правовым характером и т.д. В центре персоноцентрического типа культуры находится персона, личность, ее права и свободы, законные интересы и достоинство. Персоноцентрический тип культуры базируется, прежде всего, на дозволениях, утверждаются принципы договорных отношений ит.д. В тоже время для персоноцентрического типа культуры характерно принципиально новое, более высокое и серьезное отношение общества и личности к соблюдению обязанностей. Оба типа культуры направлены на защиту интересов, как общества, так и личности, только в принципиально различном, противоположном отношении, в одном случае при возникновении между ними коллизий приоритет отдается социальным интересам в ущерб интересам личности (социоцентризм), в другом случае - делается попытка согласовать интересы общества и личности и лишь при недостижении консенсуса приоритет отдается личности, ее правам и свободам (персоноцентризм). Эти закономерности в чем-то аналогичны соотношению дозволений и запретов в разрешительном и общедозволенном типах регулирования (главное - что лежит в основе), являются их продолжением на другом философско-культурологическом уровне анализа [4, с.35].

Таким образом, многообразие различных подходов к типологии культур свидетельствует о сложности и неоднозначности этой проблемы, что ставит перед исследователями поиск новых направлений и новых подходов.

ЛИТЕРАТУРА

1. Кучумова Е.В. Формирование правового дискурса в российской культуре конца 20 века. Автореферат диссертации на соискание ученой степени кандидата философских наук. - СПб., 2003. - С.18.

2. Лотман Ю.М. Избранные статьи: Семиотика культуры. Том 1 - Таллинн, 1992. - С. 104-105.

3. Семитко А.П. Развитие правовой культуры как правовой прогресс (проблемы теории и методологии). Автореферат на соискание ученой степени доктора юридических наук. - Екатеринбург, 1996. - С. 23-24.

4. Семитко А.П. Развитие правовой культуры как правовой прогресс. - Екатеринбург, 1996. - С. 34-35.

5. Сорокин П.А. Кризис нашего времени. // Человек. Цивилизация. Общество. - М., 1992. - С. 495-497. 